\title{
Cicloturismo no Planejamento Integrado de Cidades e o Caso da Região Metropolitana de Curitiba
}

\author{
Luiz Emerson da Cruz Saldanha \\ Lorena de Freitas Pereirab \\ Ronaldo Balassiano ${ }^{c}$ \\ Carla Conceição Lana Fraga ${ }^{d}$
}

\begin{abstract}
Resumo
O cicloturismo é reconhecido por ser uma atividade que envolve múltiplos segmentos do turismo, assim como conecta ambientes urbanos e rurais. Quando a principal motivação de uma viagem se encontra no percurso entre um destino e outro, permite-se o desenvolvimento em escala local nas regiões abrangidas pela rota de trânsito. Contudo, a implantação de roteiros turísticos para bicicleta requer uma articulação organizacional que envolva diferentes áreas de planejamento e setores da sociedade - principalmente em grandes centros urbanos. Desta forma, o presente artigo apresenta uma contribuição teórico-conceitual sobre o alinhamento do planejamento cicloviário ao turístico, com vistas ao desenvolvimento do cicloturismo. Por meio de uma revisão bibliográfica que contemplou artigos científicos e documentos estratégicos nacionais e internacionais, foram levantados conceitos orientadores de gestão e avaliadores de infraestrutura - como os polos de ciclismo e os critérios de qualidade, respectivamente. 0 estudo de caso sobre a Região Metropolitana de Curitiba foi realizado para melhor compreender a aplicabilidade destas ferramentas para o contexto brasileiro. Os resultados destacam uma perspectiva interdisciplinar para o planejamento da rede viária em relação à atratividade do destino e suas respectivas condições ambientais e demográficas.
\end{abstract}

Palavras-chave: Cicloturismo.; Planejamento urbano; Bicicleta; Mobilidade urbana; Turismo sustentável.

\section{Abstract \\ Cycle Tourism in the Integrated Planning of Cities and the Case of the Metropolitan Region of Curitiba}

Cycle tourism is an activity that involves multiple segments of tourism, as well as connecting urban and rural environments. When the primary motivation for a trip is the path between one destination and another, it is possible to reach local development in regions covered by its transit route. However, the implantation of tourist itineraries for bicycles requires an organizational articulation that involves different planning

a. Doutorando em Engenharia de Transportes pela Universidade Federal do Rio de Janeiro (UFRJ). Rio de Janeiro, Rio de Janeiro, Brasil. E-mail: luizsaldanha@pet.coppe.ufrj.br

b. Doutoranda em Engenharia de Transportes pela Universidade Federal do Rio de Janeiro (UFRJ). Rio de Janeiro, Rio de Janeiro, Brasil. E-mail: lorenafreitas@pet.coppe.ufrj.br

c. Doutor em Engenharia de Transportes pela University of Westminster (UOW). Londres, Inglaterra. Professor Titular do Programa de Engenharia de Transportes da Universidade Federal do Rio de Janeiro (UFRJ). Rio de Janeiro, Rio de Janeiro, Brasil. E-mail: ronaldo@pet.coppe.ufrj.br

d. Doutora em Engenharia de Transportes pela Universidade Federal do Rio de Janeiro (UFRJ). Professora Associada do Departamento de Turismo e Patrimônio da Universidade Federal do Estado do Rio de Janeiro (UNIRIO). Rio de Janeiro, Rio de Janeiro, Brasil. E-mail: carlota.fraga@gmail.com 
areas and sectors of society - mainly in large urban centers. Thus, this paper presents a theoretical and conceptual contribution to the alignment of cycling planning with tourism planning, with a view to the cycle tourism development. Through a national and international bibliographic review that included scientific papers and strategic documents, were raised concepts of destination management and infrastructure evaluators - such as cycling hubs and quality criteria, respectively. The case study on the Curitiba Metropolitan Region was carried out to better understand the applicability of these tools to the Brazilian context. The results highlight an interdisciplinary perspective for the planning of the road network in relation to the attractiveness of the destination and its respective environmental and demographic conditions.

Keywords: Cycle tourism; Urban planning; Bicycle; Urban Mobility; Sustainable tourism.

\section{Resumen}

\section{Cicloturismo en la Planificación Integrada de las Ciudades y el Caso de la Región Metropolitana de Curitiba}

El cicloturismo es reconocido por ser una actividad que involucra a una variedade de sectores del turismo, además de conectar los entornos urbano y rural. Cuando la principal motivación para un viaje se encuentra en la ruta entre un destino y otro, se permite el desarrollo a nivel local en las regiones cubiertas por la ruta de tránsito. Sin embargo, la implantación de itinerarios turísticos para bicicletas requiere una articulación organizativa que implique a diferentes áreas de planificación y sectores de la sociedad, sobre todo en los grandes centros urbanos. De esta forma, este artículo presenta un aporte teórico y conceptual sobre la alineación de la planificación cicloviaria con la planificación turística, a fin de impulsar el desarrollo del cicloturismo. Mediante un estudio bibliográfico que incluye artículos científicos y documentos estratégicos nacionales e internacionales, se plantearon los conceptos rectores de la gestión y evaluación de infraestructuras, como centros de ciclismo y criterios de calidad, respectivamente. El estudio sobre el caso práctico de la Región Metropolitana de Curitiba se llevó a cabo para comprender mejor la aplicabilidad de estas herramientas en el contexto brasileño. Los resultados señalan una perspectiva interdisciplinaria para la planificación de la red vial en conexión con el atractivo del destino y sus condiciones ambientales y demográficas.

Palabras-clave: Cicloturismo; Planificación urbana; Bicicleta; Mobilidad urbana; Turismo sostenible.

\section{INTRODUÇÃO}

0 acesso aos sistemas de transportes urbanos são parte integrante das condições de acessibilidade, de acordo com Cervero, Sarmiento e Jacoby (2009). Tais sistemas devem garantir a circulação com qualidade tanto para a população local como para aquela que permanece temporariamente em determinados destinos. Neste sentido, é notável a dependência que existe entre o desenvolvimento do turismo e os sistemas de transportes. Essa relação começa a ser traçada desde a origem da viagem, pois considera o deslocamento até o destino turístico, e se complementa nos deslocamentos dentro do destino em si (Palhares, 2002; Lamont, 2009).

Contudo, o aumento da demanda promovido pela atividade turística pode gerar uma sobrecarga nestes sistemas (nos quais se incluem as vias de circulação). Dada condição acarreta no reforço de externalidades negativas referentes ao padrão atual de mobilidade urbana, tais como engarrafamentos, poluição e perda 
da qualidade de vida local. Condição tal que se encontra desalinhada às novas abordagens da mobilidade que enfatizam a sustentabilidade. Entende-se que a mobilidade sustentável contempla aspectos sociais, ambientais e econômicos, podendo ser entendida como o resultado de uma mudança comportamental que acarreta em opções por modos mais eficientes e menos impactantes (Portugal, 2017). E, caminhando neste sentido, autores passam a destacar valorização dos transportes ativos (a pé e bicicleta) (Andrade \& Linke, 2017; Banister, 2008), sendo para Ritchie (1998) a bicicleta uma tendência no mercado turístico.

0 denominado cicloturismo traz aos destinos melhorias de cunho socioambientais, mas é no aspecto econômico que tem seu destaque, como mostra o exemplo dos Estados Unidos da América: as atividades relacionadas movimentaram cerca de USD 133 bilhões ao ano, promovendo a geração de cerca de 1,1 milhões de empregos (Flusche, 2012). Outros exemplos de nações que incluem do cicloturismo no planejamento público são Alemanha, Austrália, Canadá, França e Holanda. A infraestrutura associada ao cicloturismo apresenta elementos locais que podem potencializar o desenvolvimento do segmento, considerando atratividade, hospedagem, integração do transporte público às bicicletas, facilidades aos ciclistas e rede cicloviária (NTA, 2007).

É importante destacar que o incentivo ao uso de modos menos poluentes e socialmente mais justos é uma tendência mundial que pode ser observada, inclusive, nos Objetivos do Desenvolvimento Sustentável (ODS) da ONU (2015). A título de contextualização, esta proposta se alinha diretamente aos objetivos 8 ("Trabalho decente e crescimento econômico") e 12 ("Consumo e produção responsáveis"). Estes objetivos abrangem o desenvolvimento e implementação de ferramentas e políticas para promover e monitorar o turismo sustentável. Além disso, o planejamento integrado e o apoio às relações econômicas, sociais e ambientais entre áreas urbanas, periurbanas e rurais também envolvem o objetivo 11, de "Cidades e comunidades sustentáveis".

Com o cicloturismo no Brasil ainda em estágio de consolidação, considera-se o estudo de experiências internacionais para a avaliação e implementação de políticas capazes de incentivar a sustentabilidade da atividade em destinos nacionais. 0 foco principal deste artigo é, portanto, compreender as condições organizacionais para a implantação de rotas de cicloturismo em ambientes urbanos. Sendo assim, os objetivos são: (a) realizar uma contribuição teórico-conceitual sobre o alinhamento do planejamento cicloviário ao desenvolvimento do cicloturismo em áreas urbanas; e (b) a partir de um estudo de caso sobre a Região Metropolitana de Curitiba (PR), fundamentar a análise e qualificação de roteiros urbanos de cicloturismo.

No envolvimento do escopo desta proposta, o sequenciamento após esta introdução se dá em mais quatro seções, além das considerações finais. A seção que segue apresenta o referencial teórico sobre as diferentes perspectivas e dimensões para o planejamento do cicloturismo. A terceira seção relaciona as características urbanas ao planejamento do cicloturismo por meio dos conceitos chave das políticas cicloinclusivas. Em seguida, os elementos presentes no encadeamento metodológico do artigo são expostos. Por fim, a penúltima seção dispõe de um exemplo nacional, no qual o desenvolvimento do cicloturismo urbano da capital paranaense estimulou a expansão para cidades vizinhas em direção a áreas verdes do Estado. 


\section{PLANEJAMENTO INTEgRAdo PARA O CICloturismo}

A relação entre transportes e turismo é bastante investigada através de modelos sistêmicos de turismo como o de Leiper (1990), no qual ressalta a interação entre a região de origem e de destino de turistas com base na rota de trânsito e nos efeitos externos ao sistema como questões políticas, tecnológicas, socioeconômicas e culturais. Lumsdon (2000), neste sentido, indica a relevância da integração entre transportes e turismo no momento de se planejar cidades turísticas. No entanto, no Brasil ainda existe uma carência de um diálogo mais aprofundado entre os órgãos responsáveis pelos transportes e pelo turismo que resulta em inúmeras dificuldades para o estudo de impactos decorrentes de determinadas atividades turísticas (DeCastro, Saldandha \& Edra, 2016).

Um exemplo de lacunas sob uma perspectiva integrada da mobilidade urbana e o turismo pode ser destacado em algumas considerações do Índice de Competitividade do Turismo da cidade do Rio de Janeiro de 2015 - índice que funcionou por um breve período como ferramenta de análise intra e interdestinos turísticos do Brasil em diferentes dimensões (e.g. infraestrutura geral, acesso, serviços e equipamentos turísticos, monitoramento, cooperação regional etc.). Neste, ao mesmo tempo em que denota os problemas de congestionamentos nas áreas turísticas e de entorno da cidade, propõe um aumento do número de vagas para estacionamento nestas mesmas áreas (MTur, 2016). Solução que indica um movimento contrário à própria Política Nacional de Mobilidade Urbana, a qual prioriza os transportes ativos e o transporte público sobre os individuais motorizados (Brasil, 2012a).

A mobilidade urbana sustentável preconiza que o desenvolvimento de atividades e facilidades de acesso possam promover viagens realizadas com qualidade (Neves, Pereira \& Portugal, 2017), devendo destacar a importância do desencorajamento do uso de modos menos eficientes (como automóveis), ao passo que se estimule a mobilidade ativa. Neste contexto, a importância do planejamento turístico comprometido com a sustentabilidade é ressaltada, com vistas a não potencializar externalidades locais, fazendo desta prática uma atividade nociva (e em alguns casos predatória).

De acordo com Abalate e Bel (2009), turistas impactam positivamente nos sistemas de transporte público dos destinos visitados ao se deslocarem por meio destes serviços. Principalmente pelo fato de utilizá-los, em sua grande maioria, em períodos fora dos horários de maior demanda, auxiliando no aumento da taxa de ocupação dos veículos e mantendo a frequência menos custosa nos períodos de entre-picos ou noturno. Entretanto, a chegada de turistas nos horários de pico cria uma pressão de demanda no sistema de transportes, resultando em imposições negativas no uso dos serviços para os moradores locais e na experiência da viagem do próprio turistas. Sendo, assim, de extrema necessidade a integração das perspectivas do turismo e mobilidade urbana dentro do planejamento de cidades.

Em razão desta ótica, Sampaio, Grimm e Segovia (2015), ressaltaram a bicicleta como importante ferramenta para se planejar a mobilidade dos moradores e turistas de forma alinhada. Ao utilizar uma mesma rede cicloviária, atende-se e integra-se tanto motivações de deslocamento utilitárias (trabalho, compras e estudos) quanto para o lazer e o turismo. Com isto, é possível minimizar os impactos negativos no sistema de transporte (como o grande uso de veículos particulares fretados 
por parte dos visitantes) e maximizar efeitos como o maior contato dos turistas com a cidade, entre atrativos, cultura e pequenos comerciantes locais.

Compreende-se que o termo cicloturismo possui um significado abrangente no que se refere às atividades de lazer e turismo realizadas por bicicleta. Para melhor conceituá-lo, três categorias facilitam o entendimento de sua relação com os usuários (ou cicloturistas): (i) excursões, quando o ciclista realiza passeios recreativos não mais longo que um dia a lugares fora ou no seu local de residência envolvendo moradores e visitantes em um mesmo roteiro; (ii) ciclismo em férias, quando o ciclismo integra um conjunto maior de atividades em uma viagem; (iii) viagens de bicicletas (ou cicloviagens), quando a bicicleta é a principal motivação e modo de transporte de uma viagem (Zovko, 2013).

Nesta perspectiva, identificam-se distintas modalidades de destinos de cicloturismo, que requerem um planejamento intersetorial para lidar com as diferentes dinâmicas ambientais e sociodemográficas. 0 cicloturismo pode se dar em ambientes urbanos, de pequenas e médias cidades até regiões metropolitanas. A atividade também se faz presente em ambientes rurais e naturais, contornando ou penetrando áreas verdes (protegidas ou não) ou por trilhas consolidadas em Bike Parks (espaços públicos ou privados com percursos delimitados e estruturados para o uso da bicicleta). Tendo em vista a amplitude de conexões de cidades, estados e até países pela bicicleta, as rotas de cicloturismo envolvem destinos urbanos e rurais por meio de contextualizações histórico-culturais, ambientais e religiosas.

Na busca pela aproximação metodológica do planejamento do cicloturismo pelo mundo, Saldanha, Santos e Fraga (2015) levantaram documentos estratégicos orientados por políticas públicas de diferentes países com representatividade na organização da atividade. Na sequência, os autores segmentaram as iniciativas encontradas em todos os documentos em três grandes fases do planejamento do cicloturismo: (i) análise do desempenho atual da atividade; (ii) desenvolvimento da infraestrutura para o cicloturismo; e (iii) promoção da área de destino.

Todas essas três fases são essenciais para o desenvolvimento da atividade e atuam de forma interdependentes, retroalimentando-se para que o destino ou rota de cicloturismo esteja sempre atendendo às expectativas dos moradores e visitantes e respeitando os princípios da sustentabilidade turística - sobre as dimensões ambiental, econômica, sociocultural e político-institucional (MTur, 2007). A fase referente ao "desenvolvimento da infraestrutura para o cicloturismo" é a que necessita de maior alocação de recursos humanos e financeiros, por requerer obras para construção e/ou manutenção - além da necessidade de estudos de viabilidade que também consideram ações da primeira fase de "análise do desempenho atual da atividade", com pesquisas sobre a oferta e a demanda para o cicloturismo.

O entendimento do perfil da demanda e o que já se possui como oferta deve ser alinhado para orientar os investimentos no âmbito do cicloturismo. Com este foco, cinco estudos se destacam por realizar um levantamento sobre os fatores determinantes para a atividade por parte dos praticantes. 0 primeiro deles é um estudo sobre o tamanho e alcance do cicloturismo na Austrália realizado por Faulks, Ritchie e Fluker (2007), em que levantaram informações sobre o perfil dos cicloturistas nas diferentes regiões do país baseando-se em literaturas existentes e expuseram quais fatores facilitam a experiência do viajante a partir da 
recomendação de indicadores. Também na Austrália, Lamont e Causley (2010) entrevistaram aproximadamente 400 cicloturistas que responderam, além de suas características demográficas, considerações de importância de diversos itens dentro do contexto da sinalização e mapeamento de ciclorrotas. Seguindo em uma mesma vertente, Nickerson et al. (2014) analisaram o perfil de mais de 700 ciclistas norte-americanos através de questionários digitais, obtendo dados relativos aos hábitos de viagem e grau de importância de questões agregadas à realização da atividade, como condições de vias, alojamento e alimentação, atrativos turísticos e serviços de apoio.

Por fim, em dois trabalhos correlacionados realizados em Taiwan (Lee \& Huang, 2014; Lee, Chen \& Huang, 2014), foram levantadas as dimensões envolvidas na atratividade de um destino de cicloturismo. Os autores contemplaram quatro dimensões nos estudos em que entrevistaram especialistas, tomadores de decisão (poder público, iniciativa privada e academia), cicloturistas e ciclistas esportivos. Citam-se: (i) atrações turísticas, envolvendo os recursos naturais e construídos; (ii) acessibilidade, concernente à abrangência e qualidade da infraestrutura das rotas existentes; (iii) amenidades, considerando tanto os serviços de hospedagem quanto os serviços de apoio; e (iv) serviços complementares, como serviços de informação, empresas de turismo receptivo e sistemas de segurança.

Com essas dimensões de serviços e estrutura para a atratividade de um destino de cicloturismo, é válido destacar como estes destinos podem organizar estes fatores para uma gestão melhor dos recursos já existentes e no que deve alocar esforços para ganhar mais representatividade neste segmento do turismo. A Autoridade de Transporte Nacional Irlandesa (NTA, 2007) definiu três tópicos para se avaliar todos os elementos de um destino de cicloturismo, podendo este ser uma rota de cicloturismo isolada ou uma grande rede de cicloturismo estadual ou nacional - no caso deste documento, foi considerado todo o país da Irlanda. Os três tópicos citados são: portões de entrada, ciclorrotas e polo de ciclismo (cycling hub, no original em inglês).

Apesar de não utilizarem estas nomenclaturas específicas, outros países se baseiam em definições similares para seus documentos estratégicos de cicloturismo (ver LTSA, 2004; SLF, 2009; FMTBUD, 2012). Os portões de entrada são as formas de acesso que o viajante possui como opção de chegada ou saída da área de destino, iniciando ou terminando uma rota de cicloturismo - para isso, devem integrar política de transporte de bicicleta e estar conectado de alguma forma à rede cicloviária local. Estes podem ser de aeroportos e portos até terminais rodoviários e ferroviários. As ciclorrotas são todos os percursos de bicicleta que um destino de cicloturismo pode possuir, seja ele uma cidade ou uma rota completa. A classificação destas pode ser feita tanto por sua composição (se começa e termina no mesmo local ou em locais diferentes) quanto por sua abrangência (se é local, regional, nacional ou continental). Por fim, o conceito de polo de ciclismo categoriza e orienta investimentos de cidades envolvidas às rotas de cicloturismo de acordo com seu valor potencial ou consolidado sobre elementos pertinentes à prática da atividade (NTA, 2007).

Devido à sua grande malha ferroviária, a grande rede de cicloturismo que conecta mais de 40 países europeus conhecida como Euro-Velo, o planejamento do cicloturismo nestes países são induzidos pela localização de terminais ferroviários. Em 2007, a aprovação de um pacote regulatório que exigia a permissão de 
transporte de bicicleta nos vagões - salvos alguns casos específicos de restrição espacial, mesmo que através do pagamento de eventuais taxas extras, resultou em usos pareados ou até mesmo superiores do trem em relação ao carro para as rotas de cicloturismo por parte dos viajantes europeus (Weston \& Mota., 2012).

No Brasil, são menos de 30 trechos ferroviários turístico-culturais em operação segundo o MTur (2013), concentrados mais no eixo sul-sudeste. No outro lado, existe uma malha rodoviária que corta o país de norte a sul, constituídos através de uma política de desenvolvimento rodoviarista. Este segundo fator estimula o uso do automóvel próprio para realizar os deslocamentos da região de origem à região de destino, assim como potencializa as viações de ônibus tanto para as viagens ponta a ponta quanto para integrar o destino final aos portos e aeroportos mais próximos.

O Projeto de Lei no 6824 de 2010 visou estabelecer "procedimentos para o transporte de bicicletas nos ônibus utilizados nos serviços de transporte interestadual e internacional de passageiros", com prerrogativas parecidas ao pacote regulatório europeu sobre o transporte ferroviário (Brasil, 2012b). Contudo, este Projeto de Lei foi arquivado no ano de 2012 e, atualmente, o despacho de bicicletas fica a cargo não só da companhia de ônibus, como também dos próprios fiscais no momento do embarque, já que a grande maioria das companhias não possuem políticas claras em relação ao transporte de bicicleta.

As ciclorrotas, se implementadas corretamente, podem servir como catalisadores de expansão da rede cicloviária de uma cidade ou região. A Rota Verde (DuBois, 2017), que corta 400 cidades no estado canadense de Quebec e obteve uma estimativa de 1,9 milhão de usuários no ano de 2015, visa a coabitação entre os modos de transporte, motivação de viagem e diversificação desses usuários (de crianças e jovens até idosos). A concepção da ciclorrota em nível estadual abrange as vias principais e de maior interesse turístico de cada município (principalmente os de pequeno e médio porte), permitindo às prefeituras locais direcionarem os esforços às vias locais e alimentadoras para compor a rede cicloviária de forma a atender tanto às motivações utilitárias quanto de lazer/turismo de viagem.

Conforme o planejamento de rotas de cicloturismo no Brasil ainda se encontra em fase inicial (o mais antigo deles, o Circuito do Vale Europeu, teve sua inauguração em 2006), ainda existem muitas lacunas no desenvolvimento de dados e aproximação da interface do transporte e turismo. Entretanto, esta condição de incipiência é uma oportunidade para se aplicar conceitos de mobilidade urbana sustentável a estes destinos de cicloturismo em fase de desenvolvimento, potencializando o uso da bicicleta não só no setor do turismo e do lazer.

0 conceito de polo de ciclismo será explorado na seção seguinte a partir de trabalhos acadêmicos e documentos institucionais sobre o planejamento do cicloturismo em ambientes urbanos. A interface da mobilidade cicloviária e motivações de uso por turismo e lazer do usuário da bicicleta é considerada para a fundamentação teórica.

\section{A INTERFACE DO CICLOTURISMO ÀS DINÂMICAS URBANAS}

O polo de ciclismo pode ser considerado peça importante para a orientação de investimentos e de gestão do cicloturismo porque proporciona uma visão geral e integrada de todos os componentes da atividade em uma cidade ou região. 
São sete elementos que permeiam o conceito de polo de ciclismo: (a) atratividade do destino; (b) meios de hospedagem; (c) facilidades para ciclistas, como aluguel de bicicletas, oficinas de reparo e comunidade receptiva ao uso da bicicleta; (d) acesso por transporte público; (e) rede cicloviária; (f) sinalização das rotas; e (g) sistema de informação, na divulgação de mapeamento por meios físicos e digitais (NTA, 2007). Desta maneira, seja na composição de rotas em uma abrangência nacional ou estadual/regional, seja na fundamentação de caminhos de cicloturismo em âmbito local, é possível realizar análises de viabilidade e direcionar esforços no momento de planejar e tomar decisões sobre o desenvolvimento do destino.

Elementos como atratividade do destino, meios de hospedagem, facilidades para ciclistas e acesso por transporte público são relevantes para subsidiar o zoneamento sobre as áreas de interesse turístico e de confluência com a dinâmica dos moradores da cidade em seu cotidiano. Os elementos de sinalização das rotas e sistemas de informação, por sua vez, encontram-se envolvidos pelo elemento de rede cicloviária ao fundamentar uma perspectiva sistêmica no planejamento viário (Saldanha, 2017). Perspectiva que considera a transversalidade entre os setores envolvidos no cicloturismo, como transportes, urbanismo, turismo, meio ambiente e segurança pública. Neste contexto, o conceito de planejamento cicloinclusivo surge para ressaltar a necessidade de integração do uso da bicicleta no sistema de transportes de uma cidade a partir de uma ótica interdisciplinar tanto na teoria quanto na sua aplicação prática (Sagaris, 2015).

Lamont (2009), em seu estudo sobre a perspectiva sistêmica do cicloturismo, ressalta a característica de múltiplos destinos ao se realizar uma cicloviagem. Ao incluir um subsistema à Área de destino no Sistema de Turismo de Leiper (1990) que contém diversas regiões de destino turístico ligadas por rotas de trânsito secundárias entre si dentro da grande área de destino, o autor retrata a importância que o percurso tem para a prática do cicloturismo - e não apenas o destino final (ver Figura 1).

Figura 1 - Modelo sistêmico do Cicloturismo

Ambientes: físico, tecnológico, social, cultural, econômico, político etc.

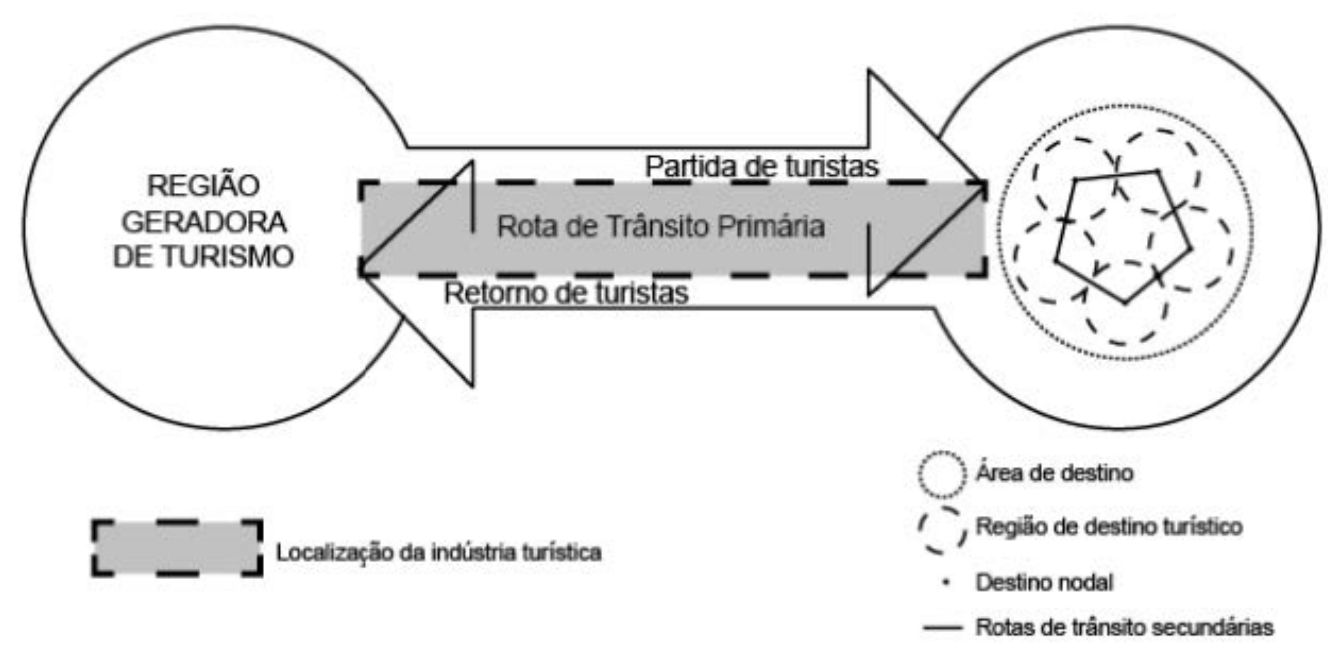

Fonte - Adaptado de Leiper, 1990, por Lamont (2009). 
Saldanha (2017) relacionou este mesmo subsistema ao fenômeno do cicloturismo urbano, retratando a Área de destino como a cidade ou região onde o viajante está hospedado. Sob esta dinâmica, as Regiões de destino turístico seriam zonas ou bairros de interesse turístico; os Destinos nodais seriam os atrativos turísticos, meios de hospedagem e/ou serviços de apoio; e as Rotas de trânsito secundárias seriam as ciclorrotas ou modos de transportes com integração ao modo cicloviário.

Quando se entende o uso de uma via para tráfego de bicicleta (se o traçado agrega todas as motivações de viagem ou somente viabiliza percursos turísticos e de lazer), é possível adaptar seu projeto geométrico após definir a função desta via (ITDP, 2017). Com este fator em mente, categorizações similares são utilizadas em guias de planejamento cicloviário europeus e australianos. Translink (2013) ressaltou como as Rotas primárias agem conectoras dos principais pontos de origem e destino e maior fluxo de ciclistas; as Rotas secundárias e Rotas locais, funcionam como conectoras de destinos menores e alimentadoras às primeiras citadas. Já o Governo de Queensland (DTMR, 2009) se baseia na distinção de Ciclorrotas regionais e Ciclorrotas locais, respectivamente proporcionais às anteriores, adicionando-se as Ciclorrotas turísticas e recreacionais, quando seu desenho cria desvios maiores para uso utilitário e requer um gerenciamento e investimentos mais direcionados para fins de turismo e lazer.

Dentro das diretrizes de planejamento cicloinclusivo, existem cinco critérios de qualidade que devem ser contemplados ao se estruturar uma rede cicloviária eficiente. Segundo o ITDP (2017), esses critérios são: (i) linearidade, visando os percursos mais curtos em termos de distância e tempo; (ii) coerência, traçado da rede vinculado com as linhas de desejo e continuidade das rotas; (iii) atratividade, além da percepção de segurança pública, uma alta densidade de destinos conectados; (iv) segurança, critério voltado aos requisitos de segurança viária; e (v) conforto, facilitando a chegada aos destinos desde sinalização à qualidade da superfície e entorno da via. Contudo, os usuários com motivação de lazer e turismo possuem perspectivas e prioridades diferentes aos ciclistas com enfoque utilitário e essa divergência deve ser considerada no momento do planejamento da rede para que não haja impactos negativos entre ambos os perfis.

Em seu documento de referência para a implantação das redes cicloviárias dentro do contexto da EuroVelo, a Federação de Ciclistas Europeus associa os critérios de qualidade segundo a perspectiva do cicloturista para auxiliar na seleção e desenvolvimento das rotas (Bodor et al., 2011). Logo, os critérios de linearidade e coerência intencionam providenciar infraestrutura ininterrupta de forma a conectar todos os atrativos ligados à temática da rota, evitando desvios desnecessários e devidamente sinalizado. No que concerne à atratividade, a conectividade entre as áreas de dispersão de cicloturistas com os atrativos naturais, histórico-culturais e afins, preocupando-se sempre em agregar a percepção positiva de segurança pública. A segurança e conforto estão relacionados, respectivamente, à preferência por vias com menor volume de tráfego motorizado e velocidades mais baixas e à busca por elevações minimizadas, com superfícies de via adequadas e boa oferta e qualidade de serviços turísticos e de apoio.

A priorização que cada perfil de uso da bicicleta assimila aos cinco critérios durante o processo de escolha do melhor trajeto em uma rede cicloviária, antes ou durante a atividade, Presto (2010) evidenciou em seu manual de políticas 
cicloviárias, conforme Quadro 1. Nesta classificação, o critério de segurança aparece tanto para a segurança viária quanto para a segurança pública e, assim, torna-se sempre imprescindível e definitivo na decisão das rotas por ambos os perfis de uso da bicicleta. Enquanto os critérios de coerência e conforto também se igualam no que se diz respeito à prioridade pelos usuários, a principal diferença se encontra nos critérios de linearidade e atratividade. Como a principal motivação do cicloturista não é apenas o destino final, mas também todos os atrativos pelo caminho e o próprio percurso em si, uma rota baseada para este perfil de usuário não precisa se preocupar com a distância e o tempo mais curto e sim com um traçado coerente conectando todos os potenciais atrativos turísticos e pontos de interesse em formato de circuito ou de ponto-a-ponto.

Quadro 1 - Critérios de qualidade prioritários para uma rede cicloviária utilitária e uma recreacional

\begin{tabular}{|c|c|}
\hline Motivação utilitária & Motivação recreacional \\
\hline Segurança & Segurança \\
\hline Linearidade & Atratividade \\
\hline Coerência & Coerência \\
\hline Conforto & Conforto \\
\hline Atratividade & Linearidade \\
\hline
\end{tabular}

Fonte - Adaptado de Presto, 2010.

Ao entender as perspectivas e prioridades referentes a cada perfil de uso da bicicleta segundo sua motivação de viagem inserido na abordagem do polo de ciclismo, a visualização para com a organização do cicloturismo urbano em um destino turístico é simplificada e se facilita a comunicação entre os mais diferentes setores públicos. A seguir, a metodologia utilizada neste trabalho será apresentada e apontará o encadeamento da visão integrada do planejamento para a análise e discussão do estudo de caso.

\section{METODOLOGIA}

O procedimento utilizado para o desenvolvimento deste trabalho se pautou no levantamento e análise documental, com vistas a embasar a compreensão sobre o planejamento estratégico de transporte e turismo. Foram elencados, além de trabalhos acadêmico-científicos, documentos estratégicos internacionais orientados por políticas públicas e publicações institucionais.

Para tanto, explorou-se os conceitos abrangidos pelo planejamento cicloinclusivo, que se refere a uma abordagem sistêmica na promoção do uso da bicicleta em relação ao sistema de mobilidade urbana de uma cidade (ITDP, 2017). Entende-se, segundo BID (2015), que esta abordagem busca ir além de apenas construir uma infraestrutura cicloviária, como envolve serviços complementares, participação cidadã, gestão integrada e aspectos normativos.

Apontado pela Figura 2, o encadeamento das perspectivas do turismo e ambientais ao planejamento urbano ajuda a fundamentar o cicloturismo dentro das políticas cicloinclusivas, seja em ambientes urbanos ou rurais. Assim, tem-se 
o uso da bicicleta que pode se dar por motivações utilitárias - como trabalho, compras e estudos - e por motivações recreativas, como lazer e turismo (Presto, 2010). Ressalta-se que a interseção destes dois universos pode ocorrer em determinados momentos como, por exemplo, quando o ciclista com motivação utilitária opte por percursos de maior desvio, mas com maior quantidade de elementos contemplativos. Optou-se por um estudo de caso brasileiro que abrangesse a complexidade de um território conurbado e permitisse uma discussão mais aplicada sobre a avaliação e viabilização de roteiros urbanos locais e regionais de cicloturismo.

Figura 2 - Estruturação do encadeamento metodológico da pesquisa

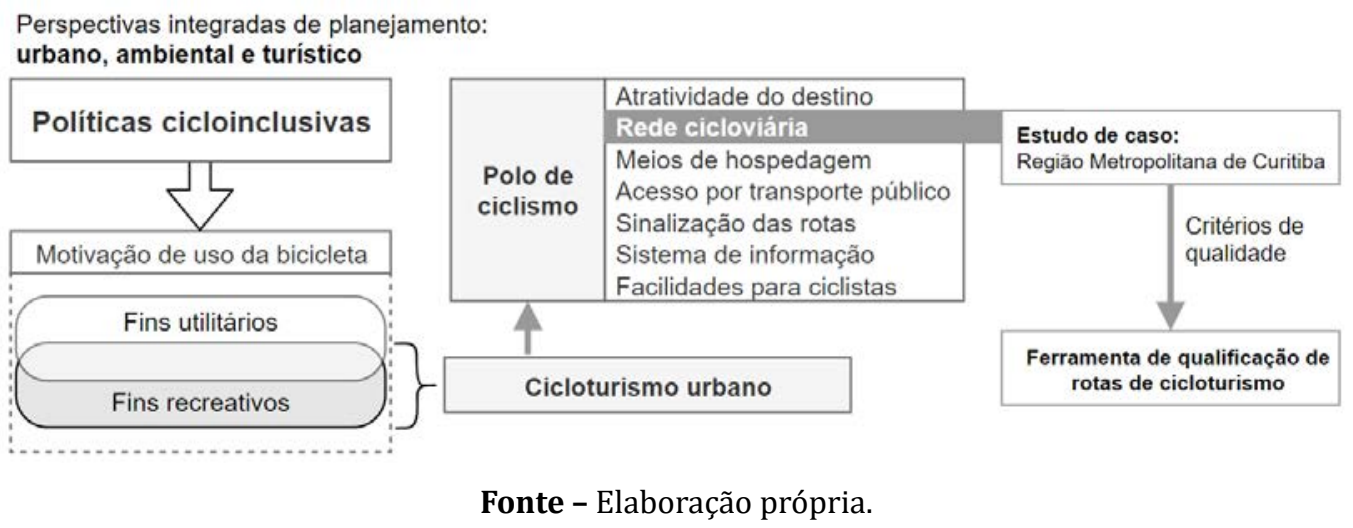

O presente trabalho destaca a evolução do cicloturismo na Região Metropolitana de Curitiba (RMC), visando compreender as oportunidades e desafios vividos pela capital paranaense e seus municípios vizinhos. Reconhecida por sua quantidade de bosques e parques próximos a polos comerciais e residenciais (Sampaio et al., 2015), a cidade de Curitiba (PR) integra o uso da infraestrutura cicloviária já existente à divulgação de atrativos turísticos locais a visitantes e moradores como forma de promover o uso da bicicleta na capital paranaense. Observa-se, no estudo de caso apresentado a seguir, que a iniciativa em conjunto dos municípios de Pinhais, Piraquara e Quatro Barras - integrantes à RMC por meio da dispersão urbana, foi construída em face à conexão dos atrativos culturais e naturais destas localidades.

\section{EVOLUÇÃO DO CICLOTURISMO NA REGIÃo METROPOLITANA DE CURITIBA}

A cidade de Curitiba elaborou o seu Plano Diretor Cicloviário no ano de 2013 já considerando o potencial do uso da bicicleta para fins de turismo e lazer ao instituir o Circuito Interparques entre uma gama de ações voltadas para o deslocamento utilitário (IPUCC, 2013). De acordo com Segovia e Grimm (2017), ao apropriar o ciclismo como ferramenta para o desenvolvimento da atividade turística assimilando linhas de desejo da população residente e de visitantes, a Prefeitura Municipal de Curitiba estabeleceu políticas públicas que promovem a mobilidade urbana sustentável enquanto incentiva a integração social e revitalização de espaços públicos. No mesmo estudo, com a implantação deste plano, constatou-se um 
aquecimento no mercado de locação de bicicleta e de agências de receptivo para a prática do cicloturismo urbano - utilizados por moradores e turistas.

O Instituto Municipal Curitiba Turismo (IMCT, 2017), em diálogo com o Instituto de Pesquisa e Planejamento Urbano de Curitiba na questão do planejamento cicloviário, instituiu o cicloturismo urbano em dois dos oito roteiros autoguiados oficiais da Coleção Curta Curitiba (distribuído não só em meios físicos pelos centros de atendimento ao turista, como divulgados eletronicamente). Juntamente a roteiros culturais, religiosos, gastronômicos, ecológicos, foram elaborados os roteiros "Curta Curitiba a pé", "Curta Curitiba Pedalando" e "Poty by bike". Estes materiais foram construídos para que os moradores e visitantes possam usufruir dos atrativos da capital paranaense através de modos ativos. O primeiro citado oferece duas opções de rotas a serem realizadas a pé pelo Centro Histórico e pelo Centro Cívico da cidade. Por sua vez, os últimos divulgam seis rotas estruturadas ao uso da bicicleta se aproveitando do $190 \mathrm{~km}$ de infraestrutura cicloviária implementada na capital paranaense (ver Figura 3).

Tabela 1 - Roteiros e extensão para o município de Curitiba

\begin{tabular}{|l|l|c|}
\hline Coleção & Nome do roteiro & Extensão \\
\hline Curta Curitiba Pedalando & Roteiro Parques e Bosques Norte & $17,5 \mathrm{~km}$ \\
\hline & Roteiro Jardim Botânico & $16,5 \mathrm{~km}$ \\
\hline & Roteiro Parque Barigui & $13,6 \mathrm{~km}$ \\
\hline & Roteiro Parques e Bosques Sul & $36,0 \mathrm{~km}$ \\
\hline & Roteiro Zoo - Jardim Botânico & $19,8 \mathrm{~km}$ \\
\hline Poty by bike & Roteiro Poty By Bike & $13,5 \mathrm{~km}$ \\
\hline & & \\
\hline Extensão total dos roteiros & & $116,9 \mathrm{~km}$ \\
\hline
\end{tabular}

Obs: Alguns trechos são sobrepostos

Fonte - Elaboração própria a partir de IMCT, 2017.

Classificados por três níveis de dificuldade, os itinerários presentes no "Curta Curitiba Pedalando" partem todos do mesmo ponto de origem (o Passeio Público, no Centro Histórico da cidade) e seguem quase que integralmente pela infraestrutura cicloviária já existentes conectando parques e bosques da cidade, principalmente os contemplados no Circuito Interparque. 0 "Poty by bike" consiste num roteiro temático de cicloturismo passando pelas obras de um dos artistas curitibanos, o Poty Lazzaroto, que possui diversos murais e painéis espalhados pela cidade. Assim, esta coleção de roteiros turísticos demonstra, não só a representatividade do planejamento turístico junto ao planejamento urbano, como a relação da atividade com os setores de meio ambiente e de cultura.

A iniciativa Ciclorrota Nascentes do Iguaçu se destaca para fins deste estudo por ser vista como uma expansão dos roteiros de Curitiba às fronteiras da Região Metropolitana com as áreas naturais em direção ao litoral do Estado do Paraná. De sua concepção até seu lançamento, em meados de 2019, visou-se um formato de turismo sustentável para a contemplação de florestas, campos, várzeas e montanhas que resguardam a bacia hidrográfica que abastece a RMC e formam o Rio Iguaçu (Bem Paraná, 2019). 
Figura 3 - Divulgação de roteiros de cicloturismo urbano da "Coleção Curta Curitiba"
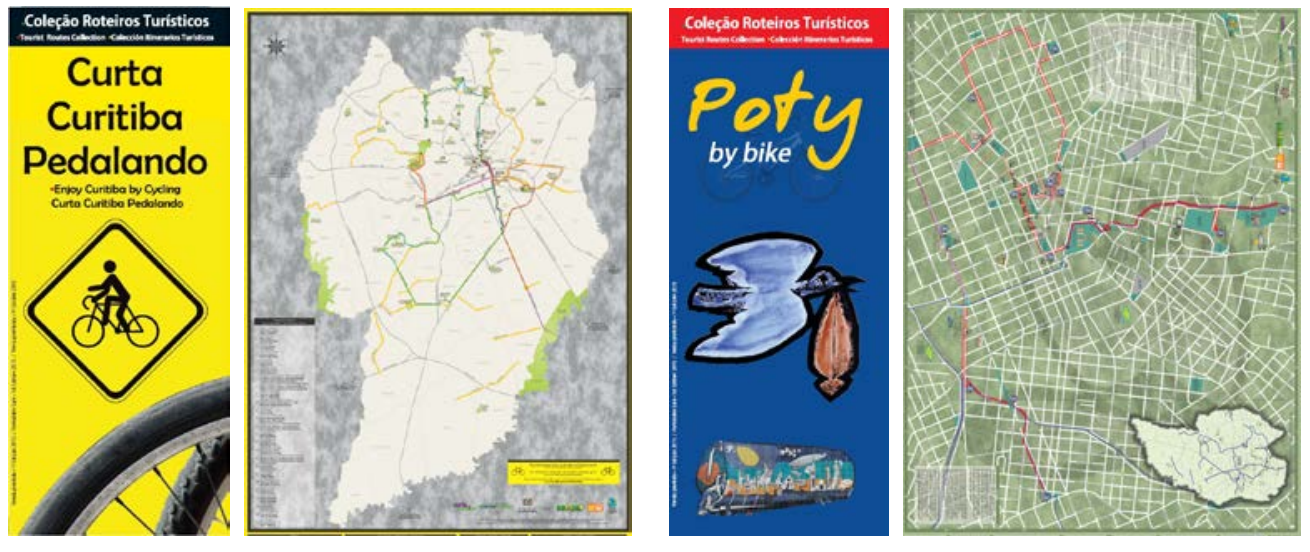

Fonte - Adaptado de IMCT, 2017.

Diversos roteiros menores visam interligar a rota principal não apenas à capital paranaense, como também a atrativos e pontos de interesse mais afastados, e permitirá uma conexão entre ambientes urbanos e rurais (Piraquara, 2019). As maiores informações sobre a situação das rotas estão focadas no estágio de sinalização direcional e informativa de roteiros consolidados previamente e seguem expostos na Tabela 2.

Tabela 2 - Roteiros e extensão para os municípios de Pinhais, Piraquara e Quatro Barras

\begin{tabular}{|c|c|c|c|}
\hline Município & Nome do roteiro & Extensão & Situação \\
\hline Todos os municípios & Rota principal & $42,1 \mathrm{~km}$ & Implementado \\
\hline \multirow[t]{4}{*}{ Pinhais } & Rota Cervejeira & $9,9 \mathrm{~km}$ & Implementado \\
\hline & Caminho das Águas & $15,6 \mathrm{~km}$ & Implementado \\
\hline & Ecológica & $7,3 \mathrm{~km}$ & Implementado \\
\hline & Curitiba-Parque das Águas & $5,9 \mathrm{~km}$ & Previsto \\
\hline \multirow[t]{5}{*}{ Piraquara } & Parque das Águas Piraquara & $18,0 \mathrm{~km}$ & Previsto \\
\hline & Mananciais da Serra & $20,0 \mathrm{~km}$ & Previsto \\
\hline & Túnel da Roça Nova & $26,4 \mathrm{~km}$ & Previsto \\
\hline & Colonização Trentina & $14,2 \mathrm{~km}$ & Previsto \\
\hline & Morro do Canal/Aldeia & $8,6 \mathrm{~km}$ & Previsto \\
\hline \multirow[t]{4}{*}{ Quatro Barras } & Montanhas & $12,0 \mathrm{~km}$ & Previsto \\
\hline & Caminho do Itupava & $9,3 \mathrm{~km}$ & Previsto \\
\hline & Graciosa Mata Atlântica & $24,3 \mathrm{~km}$ & Previsto \\
\hline & Circular Quatro Barras & $19,3 \mathrm{~km}$ & Previsto \\
\hline Total implementado & & $74,9 \mathrm{~km}$ & \\
\hline Total previsto & & $232,9 \mathrm{~km}$ & \\
\hline
\end{tabular}

Obs: Alguns trechos são sobrepostos

Fonte - Elaboração própria a partir de Piraquara, 2019. 
Entende-se que, apesar da ausência de um consórcio formalizado, a gestão dos roteiros secundários e trechos da rota principal da Ciclorrota Nascentes do Iguaçu tem a responsabilidade do munícipio nas quais estão respectivamente localizadas (Bem Paraná, 2019). Esta gestão contempla a demarcação do percurso, implementação da sinalização, manutenção e divulgação/detalhamento sobre atrativos e informações de interesse em nível local. A Figura 4 apresenta o material de divulgação turística preparado para todos os roteiros da Tabela 2, junto ao qual é integrado a um arquivo de georreferenciamento para maior exatidão dos trajetos.

Figura 4 - Material de divulgação das Ciclorrotas Nascentes do Iguaçu

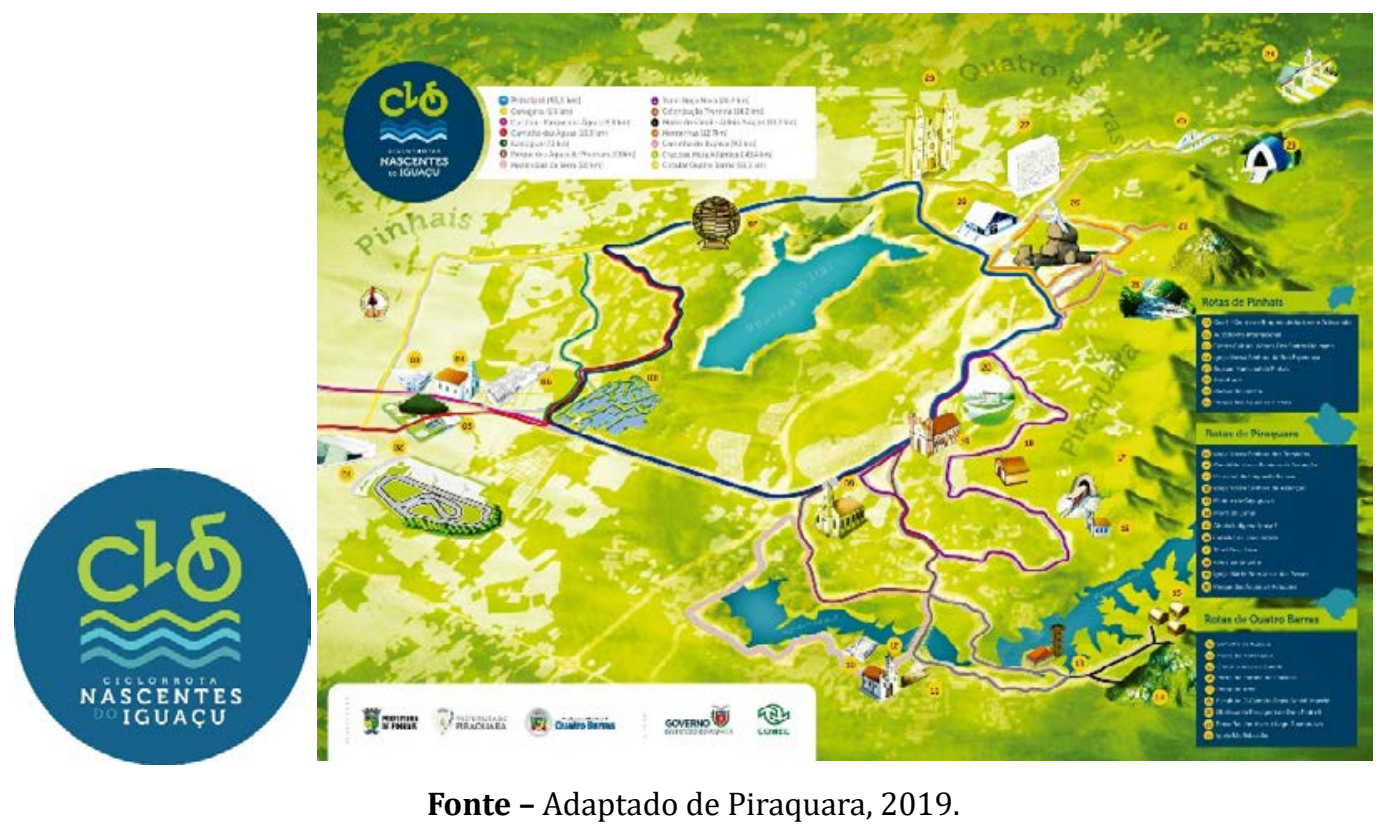

Conforme visto no Quadro 1, a segurança e atratividade são os critérios de maior peso aos fatores determinantes de uma rota de cicloturismo. Quando contemplado às dinâmicas urbanas, deve-se ter uma infraestrutura cicloviária condizente a intensidade do tráfego de modos ativos e motorizados, existência de criminalidade e necessidade de permeabilizar barreiras urbanas. Sendo assim, buscou-se a infraestrutura existente nos quatro municípios delimitados para entrelaçar aos traçados de cada roteiro levantado nesta seção.

Evidencia-se, na Figura 5, a formação de uma malha de roteiros de cicloturismo conectando o epicentro urbano da Região Metropolitana de Curitiba às Unidades de Conservação da Mata Atlântica ao Leste do Estado do Paraná. É possível observar que existe uma coerência entre a rede cicloviária existente e os roteiros implementados nas iniciativas de Curitiba, Pinhais, Piraquara e Quatro Barras. Nota-se, também, as conexões entre o ambiente construído das áreas centrais de cada município às atrações naturais em áreas mais afastadas, tal como as ligações previstas com municípios fora da RMC.

A existência de trechos não cobertos pela rede cicloviária, contudo, levanta o questionamento sobre possíveis percepções de insegurança na tentativa de abrangência de uma totalidade de atrativos turísticos. A contraposição dos roteiros de cicloturismo traçados à infraestrutura cicloviária implementada permite a identificação de potenciais pontos de conflitos entre ciclistas e veículos motorizados. 
Na delimitação deste trabalho, propõe-se esquematizar a qualificação de rotas de cicloturismo a partir da exemplificação de um estudo de caso nacional.

Figura 5 - Roteiros de cicloturismo apresentados no estudo em relação à infraestrutura cicloviária existente

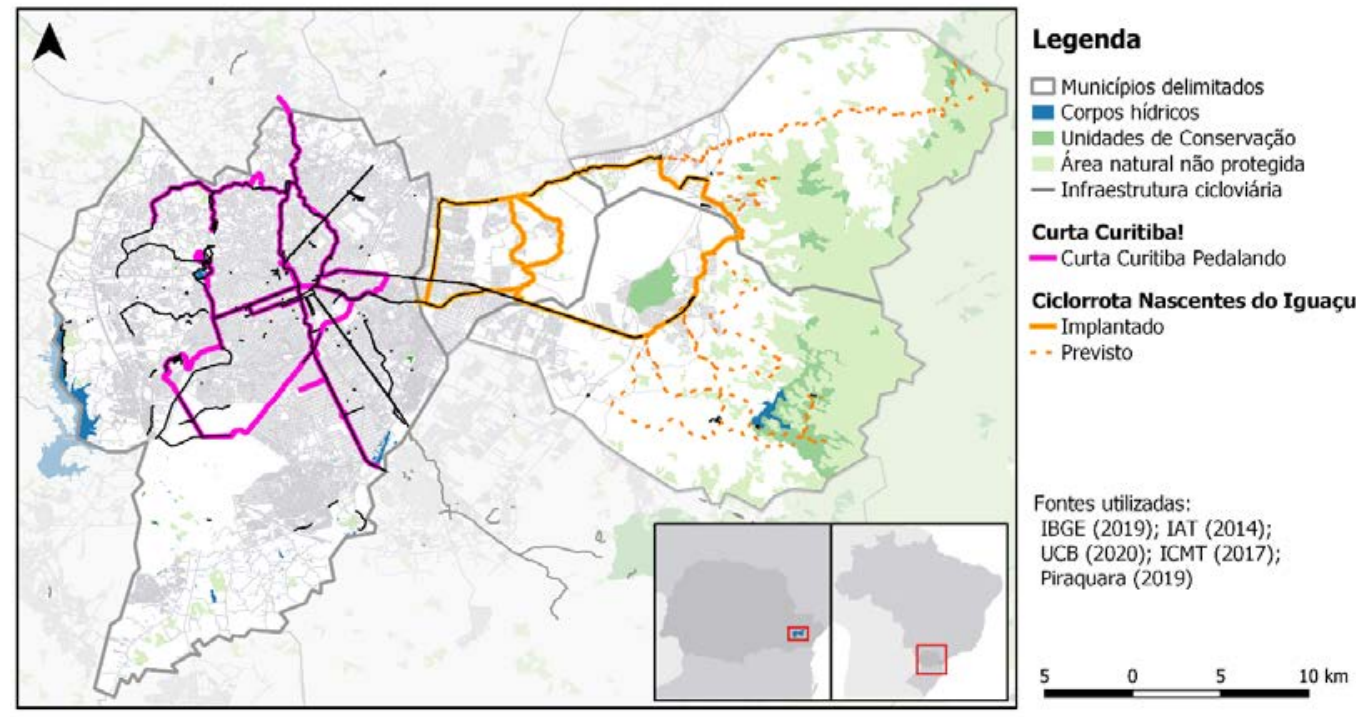

Fonte - Elaborado a partir de IBGE (2019); IAT (2014); UCB (2020); IMCT (2017), Piraquara (2019).

Os critérios de qualidade são capazes de influenciar na dinâmica intersetorial de planejamento do cicloturismo, pois conciliam as perspectivas do residente e do visitante na melhor apropriação do ambiente construído de uma cidade. A Figura 6 apresenta o esquema de qualificação para que sirva de ferramenta de avaliação de rotas estabelecidas ou de viabilização de novas rotas. Entende-se que, para a aplicação de cada critério, deva existir uma interseção entre setores de turismo, cultura, meio ambiente, urbanismo e transportes - além de uma cooperação regional consistente, no caso de rotas intermunicipais.

Figura 6 - Esquema da qualificação de uma rota de cicloturismo

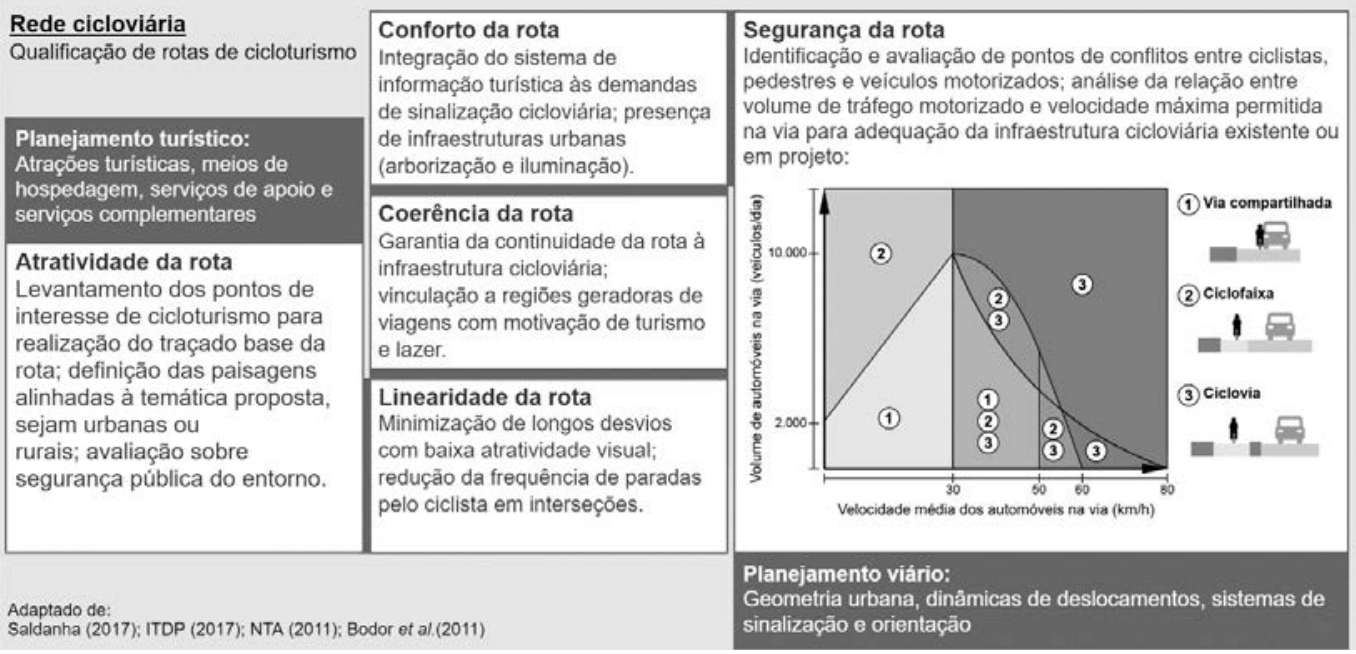

Fonte - Elaboração própria. 
Ao compreender os pontos de interesse que a rota deve abranger pelo critério de atratividade, chega-se a uma linha de desejo para orientar o traçado nas vias públicas por meio do critério de linearidade. Quando o traçado não estiver em trechos livres de tráfego motorizado, faz-se necessário que a infraestrutura cicloviária esteja de acordo com o volume e velocidade de veículos motorizados na via. Deste modo, é possível avaliar o compartilhamento ou o grau de segregação do tráfego de bicicletas, como também a necessidade de medidas de moderação de tráfego motorizado.

Além da questão da segurança, a abrangência da infraestrutura cicloviária por toda a rota de cicloturismo também se insere no critério de coerência. Este critério também incide na vinculação da rota de cicloturismo com zonas alheias ao percurso principal, mas que implicam na experiência do usuário. Como exemplo destas zonas, citam-se: concentração de meios de hospedagem, polos gastronômicos, centros comerciais e áreas turísticas indutoras do destino. Por fim, seguindo o critério de conforto, todo o planejamento viário deve acompanhar um sistema de sinalização com uniformidade local e regional, para que o usuário (residente ou visitante) consiga se orientar facilmente - sem precisar descer da bicicleta.

Dentro dos elementos do conceito de polo de ciclismo, o elemento de rede cicloviária se encontra na interface da perspectiva do planejamento viário à organização turística e gestão colaborativa da população local. Considera-se que diferentes perfis de residentes se relacione direta ou indiretamente com a atividade do cicloturismo, destaca-se: comunidades tradicionais, produtores locais, empresas de turismo receptivo, pequenos comerciantes, grupos de ciclistas, organizações da sociedade civil pró-bicicleta, pesquisadores e universidades. A aproximação destes diferentes atores na estruturação e validação de rotas de cicloturismo é fundamental para sua perpetuidade, garantindo maior eficácia no funcionamento, apoio, manutenção, promoção e monitoramento.

\section{CONSIDERAÇÕES FINAIS}

Por ser uma abordagem ainda incipiente no Brasil, a investigação teórico-conceitual do planejamento do cicloturismo se faz relevante para orientar análises de iniciativas e de estratégias para a consolidação da atividade em território nacional. Os artigos acadêmicos e documentos institucionais apresentados ao longo deste trabalho realçam necessidade de adaptação ao cenário nacional a partir da compreensão de políticas públicas federais, estaduais e municipais. 0 presente estudo de caso se deu pela perspectiva das políticas públicas da cidade de Curitiba e da articulação entre outros três municípios de sua Região Metropolitana, destacando as possibilidades de conexões entre infraestrutura cicloviária e atrativos culturais e naturais.

Nota-se, desta forma, a transversalidade da bicicleta ao planejamento do turismo como um caminho coerente na interface da mobilidade sustentável. A evolução do cicloturismo urbano na Região Metropolitana de Curitiba demonstra as possibilidades de uma apropriação coerente da infraestrutura urbana para o desenvolvimento desta atividade. No entanto, ressalta-se que a interlocução com outros elementos do polo de ciclismo é determinante para que residentes se sintam pertencentes à rota e tragam o funcionamento e apoio necessários para sua consolidação na oferta turística. 
Para que a recepção de turistas não agrave as condições de mobilidade urbana e vice-versa, faz-se necessário que a gestão municipal e a cooperação regional ocorram de forma integradas entre os diversos setores administrativos. Processos participativos de governança, por sua vez, são capazes de conciliar anseios da sociedade civil, do poder público e da academia em uma perspectiva interdisciplinar e permite uma continuidade das iniciativas a longo prazo.

Ferramentas de análise podem ser significativas para o monitoramento da qualidade das facilidades turísticas frente a estrutura implementada. 0 que propicia segurança ao usuário e oportunidades de negócios para a população residente. No caso específico do cicloturismo, as dimensões do polo de ciclismo tiveram sua relevância apontada no levantamento documental, devendo, portanto, ser considerado nos planos cicloviários municipais e nas estratégias regionais de turismo.

Espera-se que pesquisas de campo complementares possam analisar a situação em potenciais pontos de conflito e identifiquem o envolvimento da população residente nas áreas delimitadas no presente trabalho. Assim como se recomenda que novos estudos apliquem o conceito de polo de ciclismo em outros destinos urbanos e rurais, analisando rotas existentes e a viabilidade de novos percursos. No que concerne ao setor privado, o conhecimento aprofundado sobre cada dimensão de planejamento pode direcionar iniciativas relacionadas a metodologias de monitoramento da atividade, implementação de estrutura de acesso, funcionamento e apoio, e criação de campanhas de publicidade e marketing.

\section{REFERÊNCIAS}

Albalate, D., Bel, G. (2009). Tourism and urban transport: holding demand pressure under supply constraints. Universitat de Barcelona \& ppre - IREA, 2009, 38p.

Andrade, V., Linke, C.C. (2017). Cidades de Pedestres: A Caminhabilidade no Brasil e no Mundo. Rio de Janeiro: Babilônia Cultura Editorial. 240p.

Banister, D. (2008). The sustainable mobility paradigm. Transport Policy, v. 15, n. 2, p. 73-80.

Bem Paraná. (2019). Pinhais, Piraquara e Quatro Barras lançam o Ciclorrota Nascentes do Iguaçu. Referenciado de: <https://www.bemparana.com.br/noticia/pinhaispiraquara-e-quatro-barras-lancam-o-ciclorrota-nascentes-do-iguacu\#.X7Zzh2hKjIW>. Acesso em: 15 mai. 2020.

BID. Banco Interamericano de Desenvolvimento. (2015). Ciclo-inclusión em América Latina y el Caribe: Guía para impulsionar el uso de la bicicleta. Cidade do México: BID.

Bodor, A., Lancaster, E., Insall, P., Larsen, J. E., Thomé, C., Stadtherr, L. (2011). EuroVelo: Guidance on the route development process. European Cyclists' Federation, Bruxelas.

Brasil. (2012a). Lei 12.587, de 03 de Janeiro de 2012. Institui as diretrizes da Política Nacional de Mobilidade Urbana. Referenciado de:<http://goo.gl/LEvQd $>$. Acesso em: 04 dez. 2017.

Brasil. Câmara dos Deputados. (2012b). Projeto de Lei 6824/2010. Informações de Tramitação. Referenciado de: <https://goo.gl/XdWbvX>. Acesso em: 24 jan. 2018.

Cervero, R., Sarmiento, O.L., Jacoby, E. (2009). Influences of Built Environments on Walking and Cycling: Lessons from Bogotá. International Journal of Sustainable Transportation, n. 3, v. 4, pp. 203-226. 
DeCastro, J., Saldanha, L., Edra, F.P.M (2016). Mobilidade cicloviária: a convergência entre o urbano e o turístico. IN: ANDRADE, V.; RODRIGUES, J.; LOBO, Z. (ORGs). Mobilidade por bicicleta no Brasil. Rio de Janeiro: PROURB/UFRJ. Referenciado de: <goo.gl/9s03ee>. Acesso em: 05 nov. 2016.

DTMR. Department of Transport and Main Roads. (2009). A guide to signing cycle networks. DMTR: Queensland.

DuBois, A. J. (2017). Opportunities and barriers for innovative cycling planning in small cities: learning from the "Route Verte" network in Quebec. Velo-City Conference ArnhemNijmegen. Referenciado de: <https://goo.gl/KkxXQW>. Acesso em: 04 dez. 2017.

Faulks, P., Ritchie, B., Fluker, M. (2007). Cycle Tourism in Australia: An investigation into its size and scope. Sustainable Tourism CRC. Brisbane.

Flusche, D. (2012). Bicycling Means Business: The Economic Benefits of Bicycle. Advocacy Advance: Tools to Increase Biking and Walking. League of American Byclists. Washington.

FMTBUD, Federal Ministry of Transport, Building and Urban Development. (2012). National Cycling Plan 2020 - Joining forces to evolve cycling. Federal Ministry of Transport, Building and Urban Development. Berlim.

IAT. Instituto Água e Terra. (2014). Áreas Estratégicas para a Conservação da Biodiversidade. Dados georreferenciados. Referenciado de: $<$ http://www.iat.pr.gov.br/Pagina/Dadose-Informacoes-Geoespaciais-Tematicos>. Acesso em: 10 jul. 2020.

IBGE. Instituto Brasileiro de Geografia e Estatística. (2019). Base de Faces de Logradouros do Brasil. Dados georreferenciados. Referenciado de: <shorturl.at/aimH4>. Acesso em: 04 mai. 2020.

IMCT. (2017). Instituto Municipal Curitiba Turismo. Disponível em: <http://www.turismo. curitiba.pr.gov.br/>. Acesso em: 04 mai. 2020.

IPPUC. (2013). Plano Cicloviário de Curitiba. Prefeitura de Curitiba. Referenciado de: http://www.ippuc.org.br/default. php. Acesso em:15 jan. 2018.

ITDP. (2017). Instituto de Políticas de Transporte e Desenvolvimento. Guia de Planejamento Cicloinclusivo. Referenciado de: https://goo.gl/4hsXaS . Acesso em: 10 jul. 2017.

Lamont, M. (2009). Independent bicycle tourism: A whole tourism systems perspective. Tourism Analysis, v. 14, n. 5.

Lamont, M., Causley, K. (2010). Guiding the way: Exploring cycle tourists' needs and preferences for cycling route maps and signage. Annals of Leisure Research, v. 13, n. 3.

Lee, C.-F., Chen, P.-T., Huang, H.-I. (2014). Attributes of Destination Attractiveness in Taiwanese Bicycle Tourism: The Perspective of Active Experienced Bicycle Tourists. International Journal of Hospitality and Tourism Administration, v. 15, n. 3, 2014a.

Lee, C.-F., Huang, H.-I. (2014). The Attractiveness of Taiwan as a Bicycle Tourism Destination: A Supply-Side Approach. Asia Pacific Journal of Tourism Research, v.19, n. 3.

Leiper, N. (1990). Tourism systems: an interdisciplinary perspective. Palmerston North: Department of Management Systems, Business Studies Faculty, Massey University.

LTSA. Land Transport Safety Authority. (2004). Cycle Network and Rout Planning Guide. Auckland.

Lumsdon, L. (2000). Transport and Tourism: Cycle Tourism - A Model for Sustainable Development? Journal of Sustainable Tourism, v. 8, n. 5, p. 361-377.

MTur. Ministério do Turismo. (2016). Índice de Competitividade do Turismo Nacional: Rio de Janeiro 2015. Ministério do Turismo: Brasília.

MTur. Ministério do Turismo. (2007). Programa de Regionalização do Turismo - Roteiros do Brasil: Turismo e Sustentabilidade. Brasília: Ministério do Turismo. 
MTur. Ministério do Turismo. (2013). Trens turísticos em Operação no Brasil. Referenciado de: <https://goo.gl/6nqKNu>. Acesso em: 22 jan. 2018.

Neves, J. M. J., Pereira, L. F., Portugal, L. S. (2017). Mobilidade com qualidade. In: Portugal, L. S. (Org.) Transporte, Mobilidade e Desenvolvimento Urbano. 1a Edição, Rio de Janeiro: Elsevier.p. 319-336.

Nickerson, N. P. et al. (2014). Analysis of Touring Cyclists: Impacts, Needs and Opportunities for Montana Institute for Tourism and Recreation Research Publications. Missoula.

NTA. National Transport Authority. (2007). A strategy for the development of Irish Cycle Tourism: Conclusions Report. Dublin.

ONU, Organização das Nações Unidas. (2015). Objetivos do Desenvolvimento Sustentável. Referenciado de: https://nacoesunidas.org/pos2015/agenda2030/. Acesso em: 22 jan. 2018.

Palhares, G. L. (2002). Transportes Turísticos. 2. ed. São Paulo: Aleph.

Piraquara. Prefeitura de Piraquara. (2019). Ciclorrotas Nascentes do Iguaçu. Referenciado de: <http://www.piraquara.pr.gov.br/turismo/Ciclorrotas-Nascentes-do-Iguacu-26-11816. shtml>. Acesso em: 10 jul. 2020.

Portugal, L.S. (2017). Transporte, Mobilidade e Desenvolvimento Urbano. 1aㅡ Edição, Rio de Janeiro: Elsevier. 336 p.

Presto. (2010). Cycling Policy Guide: Cycling Infrastructure. EU's Intelligent Energy. Referenciado de: <http://www.presto-cycling.eu/>. Acesso em: 02 dez. 2017.

Ritchie, B. W. (1998). Bicycle tourism in the South Island of New Zealand: planning and management issues. Tourism Management, v. 19, n. 6.

Sagaris, L. (2015). Lessons from 40 years of planning for cycle-inclusion: Reflections from Santiago, Chile. Natural Resources Forum, v. 39, n. 1, p. 64-81.

Saldanha, L. E. C. (2017). Políticas Cicloinclusivas e Cicloturismo: 0 caso do Rio de Janeiro. Programa de Engenharia de Transportes. Dissertação de Mestrado. Rio de Janeiro: Universidade Federal do Rio de Janeiro.

Saldanha, L., Santos, M. P. S., Fraga, C. (2015). O papel de instrumentos de planejamento para o desenvolvimento do cicloturismo em âmbito internacional. XIII Rio de Transportes.

Sampaio, C. A. C., Grimm, I. J., Segovia, Y. N. S. (2015). Mobilidade Urbana Sustentável e o Turismo: Análise Comparativa Brasil, Holanda e Dinamarca. XII ANPTUR.

Segovia, Y., Grimm, I. (2017). O cicloturismo na perspectiva da gestão urbana na cidade de Curitiba (PR). 2016. IN: Cicloturismo urbano em foco / organizadores, Fátima Priscila Morela Edra, Juliana de Castro, Luiz Emerson da Cruz Saldanha. - Niterói: FTH/UFF.

SLF. Stichting Landlijk Fietsplatform. (2009). Zicht op Nederland Fietsland. Amersfoort.

Translink. (2013). Get There By Bike! Wayfinding Guidelines for Utility Cycling in Metro Vancouver. Applied + Alta Planning. Vancouver.

UCB. União de Ciclistas do Brasil. (2020). CicloMapa: Mapa colaborativo de infraestruturas cicloviárias. Referenciado de: <http://ciclomapa.org.br/>. Acesso em: 10 jul. 2020.

Weston, R., Mota, J. C. (2012). Low Carbon Tourism Travel: Cycling, Walking and Trails. Tourism Planning and Development, v. 9, n. 1.

Zovko, I. (2013). Cycle Tourism: Opportunities for the Scottish economy. Transform Scotland. Edimburgo, p. 52. 


\section{CONTRIBUIÇÕES}

Luiz Emerson da Cruz Saldanha: Definição do problema de pesquisa e objetivos, desenvolvimento da proposição teórica, realização da revisão bibliográfica e fundamentação teórica, escolha dos procedimentos metodológicos, coleta e análise de dados, elaboração de tabelas, gráficos e figuras, redação e adequação do manuscrito às normas da RTA.

Lorena de Freitas Pereira: Definição do problema de pesquisa e objetivos, desenvolvimento da proposição teórica, revisão crítica redação e adequação do manuscrito às normas da RTA.

Ronaldo Balassiano: Definição do problema de pesquisa e objetivos, desenvolvimento da proposição teórica, escolha dos procedimentos metodológicos e revisão crítica do manuscrito.

Carla Conceição Lana Fraga: Definição do problema de pesquisa e objetivos, desenvolvimento da proposição teórica, escolha dos procedimentos metodológicos e revisão crítica do manuscrito. 